\title{
Sentience, Rationality, and Moral Status: A Further Reply to Hsiao
}

\section{Stephen Puryear}

\begin{abstract}
Timothy Hsiao argues that animals lack moral status because they lack the sort of higher-level rationality required for membership in the moral community. Stijn Bruers and László Erdős have already raised a number of objections to this argument, to which Hsiao has replied with some success. But I think a stronger critique can be made. Here I raise further objections to three aspects of Hsiao's view: his conception of the moral community, his idea of root capacities grounded in one's nature, and his explanation of why cruelty is wrong. I also argue that sentience is a more plausible candidate for the morally salient capacity than rationality.
\end{abstract}

Keywords Sentience, Rationality, Moral Status, Animals, Vegetarianism

\section{Introduction}

Timothy Hsiao (2015a) argues that moral status belongs only to members of the moral community; that membership in the moral community requires a fairly high degree of rationality; that animals lack this degree of rationality; and thus that animals lack moral status. In response, Stijn Bruers (2015) and László Erdős (2015) have lodged a number of objections against Hsiao's argument, to which he (Hsiao 2015b) has replied with some success. I sympathize with these critics, but I do not think they have been as effective as they could have been in identifying the flaws in Hsiao's reasoning. I would therefore like to add some further criticisms of my own.

\section{The Moral Community}

Hsiao's main argument purports to show that animals lack moral status because they lack the sort of rationality required for membership in the moral community. Neither Bruers nor Erdős have much to say about this argument in their replies (cf. Hsiao 2015b: 1130-1131), but I believe it is worth considering in some detail. Let us start with a reconstruction:

1. Morality concerns purposeful action in pursuit of one's flourishing.

2. The moral community consists of just those beings who are capable of what morality concerns.

3. Only rational agents can act purposefully in pursuit of their flourishing.

4. Only rational agents can be members of the moral community. (from $1,2,3$ )

5. Only members of the moral community have moral status.

6. Only rational agents have moral status. (from 4, 5)

7. Animals are not rational agents.

8. Animals do not have moral status. (from 6,7) 
So construed, the argument is valid. Its success therefore hinges on the plausibility of its assumptions, namely, (1), (2), (3), (5), and (7). Let me say right out of the gate that I want to grant for the sake of argument that what Hsiao has in mind when he speaks of a purposeful pursuit of one's flourishing requires a degree of rationality that animals lack. So I have no beef with either (3) or (7). Further, I propose to grant (2) and (5) for the sake of argument. From my perspective, then, the crux of the argument is premise (1). Is this a plausible premise?

No, it is not. For one thing, even if morality does concern the purposeful pursuit of one's flourishing, it arguably does not concern only this. It also concerns one's treatment of others, and in particular, it concerns the phenomena of wronging and being wronged. Accordingly, it can plausibly be argued that anyone who is capable of being wronged is capable of what morality concerns, and thus, per (2), belongs to the moral community. From this perspective, membership in the moral community cannot be decided just by reflecting on the nature of purposeful pursuit of flourishing; we must also consider what it means to be wronged, and who exactly is capable of being wronged. If it turns out that animals are capable of being wronged, then morality will concern them too, and they will be members of the moral community.

It should be no surprise that Hsiao reaches the ratiocentric (or anthropocentric) conclusion that only rational beings have moral status; for he essentially builds this ratiocentrism into his argument from the start. Of course if we assume that morality is (exclusively) about a kind of rational pursuit of flourishing, then animals will be excluded from the scope of morality. The question is: Why should we accept this rather parochial conception of morality?

On this point Hsiao's argument is weak. Consider, for instance, this consideration, which he offers in support of (1): "Many disputes within moral theory center around questions pertaining to the content of flourishing and how it should be pursued. This presupposes that those in the moral community are able to act for moral reasons" (2015a: 284-285). But notice the subtle slide here. Many disputes within moral theory concern a phenomenon that presupposes moral agency; therefore all members of the moral community must have rational agency. This is a blatant non sequitur. The fact that many moral disputes center around such questions shows at most only that some members of the moral community are rational agents. It may well be that many other moral disputes have nothing to do with the why or what of the rational pursuit of flourishing.

Here is another observation Hsiao (2015b: 1129) offers in support of premise (1): "It is hard to see what else morality could be if not a code of conduct that exists for the sake of guiding purposeful action in pursuit of one's flourishing." I find this statement rather puzzling. To be sure, this sort of eudaimonistic conception of ethics dominated the landscape from at least the days of Aristotle up through the seventeenth century. But at least since the eighteenth century, many other conceptions of morality have been advanced. According to some, morality is about maximizing total utility or happiness, not only one's own but that of others too. According to others, morality is about respect for the moral law, and must be sharply distinguished from selfinterest. Still others hold that morality is simply about love, sympathy, or compassion for others. And these do not exhaust the options. It would be one thing to argue that these are inferior conceptions of morality. But to assume the eudaimonistic conception from the outset, without even acknowledging these alternatives, renders Hsiao's argument dialectically impotent. 


\section{Root Capacities}

Views like Hsiao's face the problem of what to say about marginal cases such as infants and the severely mentally disabled, who cannot reason but are generally thought to have moral status. Like many before him, Hsiao claims that such individuals can be considered rational in virtue of their human nature. More precisely, he admits that they lack an immediately exercisable capacity for rationality, but maintains that they nonetheless possess a "root capacity" for rationality in virtue of their membership in a certain natural kind, namely, that of human (2015a: 286). He describes this root capacity as a "higher-order capacity" in which more immediately exercisable "lower-order capacities" are grounded (2015a: 287). Thus, every more developed or more immediately exercisable capacity for rationality is ultimately grounded in the root capacity which belongs to all humans in virtue of their possession of a human nature.

Bruers (2015: 709-713) and Erdős (2015) have already raised a number of objections to this notion of root capacities, some of which I endorse. But here I want to add a few more.

First, the idea of a root capacity grounded in one's nature seems rather far-fetched. Consider the example of a human born without eyes. Since sight belongs to human nature just as much as rationality, Hsiao's view implies that this human has a root capacity to see. But what sense can we make of the suggestion that a being without eyes has the capacity to see? If we say that a person whose eyes are closed or who is suffering from temporary blindness has the capacity to see, even though they cannot see in the moment, this judgment is at least partly grounded in the fact that the person has eyes that are intact and capable of facilitating sight. In contrast, the person born without eyes does not even possess the organs that would be required for sight. In such a case, the person cannot plausibly be said to have even a root capacity for sight, despite the fact that they have a nature or essence to which sight belongs.

Second, it should be noted that we can accept Hsiao's idea that there are different hierarchies of capacities, with different degrees of realization, without going so far as to accept that there are root capacities grounded in one's nature or membership in some natural kind. For example, we could hold that a person's more developed (i.e., more immediately exercisable) capacities are ultimately grounded in capacities they have not in virtue of their nature but in virtue of their actual bodily organs. Thus, the fact that a person has a capacity for awareness even while unconscious would be grounded in the fact that they have an intact brain. The fact that a person has a capacity for sight even while in pure darkness would be grounded in the fact that they have an intact visual system. On such a view, we could still explain why a person in a coma has moral status, but without resorting to the strange idea of a root capacity grounded in one's nature.

Third, in his rejoinder to Bruers and Erdős, Hsiao (2015b: 1136) claims that, even if the idea of a root capacity for rationality is nonsense, nothing significant follows for his core thesis that moral status is grounded in the ability to reason. But this is just not true. It would indeed be a major strike against the theory that moral status is grounded in rationality if it turned out to entail that infants, small children, and the severely mentally disabled lack moral status. The plausibility of Hsiao's position therefore depends essentially on his prospects for solving the problem of marginal cases. And if those prospects hinge on making sense of the idea of a root capacity for rationality grounded in human nature, then so much the worse for his position. Indeed, it is a major advantage of the sentience view that it can explain why these marginal cases have moral status without appealing to any such ethereal capacities. 


\section{Cruelty}

Finally, toward the end of his paper, Hsiao (2015a: 289-290) addresses the concern that, if animals lack moral status, cruelty toward them will not be morally wrong. To this he replies with a version of the traditional view that cruelty towards animals harms them, which in turn harms humans, indeed harms humans morally, thus rendering the cruelty wrong. But in elaborating this reply, Hsiao steps into a pitfall. He remarks that "Cruelty, whatever else it may be, consists of practices that inflict needless or excessive suffering (i.e. suffering beyond what is required) or suffering for its own sake" (p. 289). But earlier in the paper, Hsiao concedes for the sake of argument that "eating meat isn't nutritionally necessary" (p. 279). To be sure, he also notes that "one [...] might question the premise that we can nourish ourselves without eating meat" (p. 279). But that would be a tough row to hoe. It is now widely recognized that well-planned vegetarian diets are nutritionally adequate for at least most humans (see, e.g., Craig and Mangels 2009). So Hsiao is wise to concede this premise. But here is the rub. If eating meat is not necessary for human nutrition, then the suffering we cause the animals we raise for meat is indeed needless and beyond what is required. By Hsiao's own definition, contemporary meat production is cruel, and thus wrong. And from here it is a short step to the conclusion that one who (knowingly) supports these industries by purchasing their products when suitable alternatives are available thereby participates in the cruelty. This flies in the face of Hsiao's claim that "It is permissible to eat meat even if eating meat is not necessary to meet the end of nutrition" (2015a: 290; cf. 2015b: 11271128).

\section{Sentience and Moral Status}

In addition to arguing for his ratiocentric view, Hsiao opposes the currently popular theory that sentience is sufficient for moral status. His main criticism of this theory is that its proponents have failed to establish a conceptual connection between sentience and moral status (2015a: 282284; 2015b: 1132-1133). But I believe the prospects for establishing such a connection are better than Hsiao realizes.

In the first place, note that proponents of the sentience view can employ the same sort of topdown strategy Hsiao uses to establish a connection between rationality and moral status. Specifically, Hsiao supposes that morality essentially concerns a purposeful pursuit of flourishing, from which he then derives the conclusion that moral status requires rationality. In the same way, friends of the sentience criterion could suppose that morality concerns (inter alia) suffering, perhaps the suffering of others in particular. They could then derive the conclusion that sentience is sufficient for moral status by an argument analogous to Hsiao's, to wit:

1'. Morality concerns suffering (i.e., experiencing pain).

$2^{\prime}$. The moral community consists of just those beings who are capable of what morality concerns.

3'. All sentient beings are capable of suffering (i.e., experiencing pain).

4'. All sentient beings are members of the moral community. (from 1', 2', 3')

5'. All members of the moral community have moral status. 
6'. All sentient beings have moral status. (from 4', 5')

7'. Many animals are sentient beings.

$8^{\prime}$. Many animals have moral status. (from $6^{\prime}, 7^{\prime}$ )

In this way, Hsaio's opponents can establish just as clear a connection between sentience and moral status as he purports to establish between rationality and moral status. This underscores the importance for the debate about the moral status of animals of our choice of a conception of morality.

But I think proponents of the sentience view can do even better. Consider this argument:

1". All beings who are capable of being wronged have moral status.

$2 "$. Beings who are caused to suffer (i.e., to experience pain) out of malice or a callous indifference toward them are thereby wronged.

3". Many animals are capable of being caused to suffer (i.e., to experience pain) out of malice or a callous indifference toward them.

4". Many animals have moral status. (from 1", 2", 3")

Obviously I cannot argue for these premises in any detail here, but I at least want to comment briefly on their plausibility. Concerning (1"), I would note simply that it is hard to imagine someone who is capable of being wronged but who lacks moral status. So $\left(1^{\prime \prime}\right)$ seems clearly true. As for $\left(3^{\prime \prime}\right)$, it seems that very few philosophers or biologists these days would deny that many animals are capable of experiencing pain, and I doubt anyone would deny that they can be the objects of malice or indifference. Hence, ( $\left.3^{\prime \prime}\right)$ also seems entirely plausible. This brings us to the key premise of the argument, $\left(2^{\prime \prime}\right)$. What can be said on its behalf? To be sure, it is by no means easy to argue for such a claim. Indeed I am tempted to say that $\left(2^{\prime \prime}\right)$ is a fundamental, self-evident truth that can be elucidated but for which we cannot really give a substantive argument (cf.

Bruers 2015: 715). To the extent that we can elucidate and argue for this claim, I have attempted to do so elsewhere (Puryear forthcoming), and I will not repeat myself here. Instead I will simply note that many philosophers have found this thesis deeply intuitive. Indeed it seems to be much more widely accepted among philosophers these days than Hsiao's starting point that morality is exclusively concerned with the pursuit of one's own flourishing. Hence, I think this argument does a better job of establishing a conceptual connection between sentience and moral status than Hsiao manages to establish between rationality and moral status.

In both the original article and his rejoinder, Hsiao (2015a: 282-284; 2015b: 1128-1129) objects to the sentience view on the ground that, if causing pain is wrong or morally bad because it constitutes a form of harm, then, absurdly, many non-sentient beings will also have moral status, because they too can be harmed. For instance, plants, bacteria, computers, and many other non-sentient things can be harmed. So if being subject to harm is the mark of moral status, then plants, bacteria, and computers will all have moral status. But no one thinks computers have moral status, and hardly anyone thinks plants and bacteria have moral status. Hence, sentience cannot be what grounds moral status.

In effect, this objection asks why it is suffering in the feeling pain sense that constitutes a wrong, as opposed to suffering in the broader sense of being worse off (as if we were to speak of one's work suffering due to personal distractions, or a plant suffering due to lack of water or 
sunlight). But here I think the sentientist has a plausible reply. For when something suffers in the sense of being worse off, we consider this bad only if it makes a difference to someone's experience of the world. If someone contracts an illness that causes some system in their body to function suboptimally, but this diminished functioning has no effect whatever on what the person feels, that is, on the person's pleasures and pains, then we do not consider the diminished functioning bad. But if the diminished functioning does detract from their pleasure or add to their pain, then we do consider it bad. Hence, it seems entirely reasonable to suppose that the kind of harm or suffering that is relevant to wrongdoing is specifically the kind that involves experiencing pain or displeasure.

On a related note, Bruers (2015: 714-715) plausibly suggests that sentience matters morally because sentience implies preferences, and preferences matter to those who have them. To this Hsiao (2015b: 1133) replies that things matter to non-sentient beings too. Thus: "Having an adequate source of knowledge certainly matters to a plant's well-being, having a nutrient rich environment certainly matters to a bacterium's well-being, and having a functional compressor certainly matters to an air conditioner's well-being." And again: "Water is important to a plant; a compressor is important to an air conditioning unit; nutrients are important to a bacterium." But this reply conflates the distinction between mattering-to and mattering-for (and the corresponding distinction between important-to and important-for). Roughly, to matter for something is to be required for its well-being or proper functioning; to matter to something is to be valued or preferred by that thing. So a functional compressor does matter for the proper functioning of an air conditioner. But to speak of a functional compressor mattering to an air conditioner, as if the air conditioner values or has a preference for such a compressor, is nonsense.

\section{Conclusion}

By now I hope it is clear that Hsiao's case for the moral permissibility of using animals for food is deeply problematic. First, his argument for the conclusion that animals lack moral status fails because its crucial premise is insufficiently supported and, moreover, implausible. Second, Hsiao's appeal to the idea of a root capacity for rationality that all humans have in virtue of being human is also implausible. Since this leaves him without a viable explanation of how young and severely mentally disabled humans could have moral status, it casts serious doubt on his ratiocentric conception of morality. Third, Hsiao's attempt to explain why cruelty is immoral, together with his concession that humans do not need meat for nourishment, seems to commit him to precisely the view he wants to deny, namely, that eating meat is immoral. In addition, I have argued that proponents of the sentience view can plausibly answer Hsiao's challenge to establish a conceptual connection between suffering and moral status. Further, they can readily account for the moral status of those humans who are sentient but lack rationality, such as infants. In view of these points, I conclude that Hsiao's ratiocentric position is deeply implausible and that we would do better to accord moral status to all sentient beings, including most animals. 


\section{References}

Bruers, S. (2015). In defense of eating vegan. Journal of Agricultural and Environmental Ethics, 28, 705-717.

Craig, W. \& Mangels, A. (2009). Position of the American Dietetic Association: vegetarian diets. Journal of the American Dietetic Association, 109(7), 1266-1282.

Erdős, L. (2015). Veganism versus meat-eating, and the myth of "root capacity": a response to Hsiao. Journal of Agricultural and Environmental Ethics, 28, 1139-1144.

Hsiao, T. (2015a). In defense of eating meat. Journal of Agricultural and Environmental Ethics, $28,277-291$.

Hsiao, T. (2015b). A carnivorous rejoinder to Bruers and Erdős. Journal of Agricultural and Environmental Ethics, 28, 1127-1138.

Puryear, S. (forthcoming). Schopenhauer on the rights of animals. European Journal of Philosophy. 